\title{
Predicting Voting Behavior of Young Adults: The Importance of Information, Motivation, and Behavioral Skills
}

\author{
Demis E. GLASFORD ${ }^{1}$ \\ University of Connecticut
}

\begin{abstract}
The information-motivation-behavioral skills (IMB) model has been shown reliably to predict and change a number of behaviors (Fisher \& Fisher, 2000). In light of low voter turnout among young adults, the present research examines the utility of the IMB model to predict voting behavior among this population. The predictive validity of the IMB model for voting behavior was tested, as well as its unique contribution to explaining voting behavior, over and above the theory of reasoned action (Ajzen \& Fishbein, 1980) and the theory of planned behavior (Ajzen, 1985). As expected, the variables specified by the IMB model uniquely predicted intention to vote (Study 1) and voting behavior (Study 2), over and above the 2 other models.
\end{abstract}

The strength of a democratic system lies in its ability to represent all people of the nation equally. Although many view the United States as the epitome of what a democracy should be, voter turnout in the U.S. consistently ranks far below turnout in other developed countries (Jackman, 1987; Wolfinger, Glass, \& Squire, 1990). In the 2000 and 2004 U.S. presidential elections, a mere $55 \%$ of eligible voters cast ballots; a far lower percentage than the modern standard of $63 \%$ cast in the 1960 presidential election (Wattenberg, 2005). Thus, close to half of the population does not exercise the right to vote and, therefore, many people are not represented in the current democratic system.

\section{Youth Political Engagement}

The consistent finding that voter turnout is low in the U.S. has generated a great deal of research exploring the antecedents to voting (for reviews, see Blais, 2000; Schlozman, 2002). Considerable evidence has suggested that voter turnout varies significantly across different groups (Wolfinger \& Rosenstone, 1980). A group that consistently fails to turn out to vote is younger citizens (i.e., 18-24 years of age), whose turnout is reliably lower

${ }^{1}$ Correspondence concerning this article should be addressed to Demis E. Glasford, who is now at the Department of Psychology, John Jay College, 445 West $59^{\text {th }}$ Street, New York, NY 10019. E-mail: dglasford@jjay.cuny.edu

\section{8}

Journal of Applied Social Psychology, 2008, 38, 11, pp. 2648-2672.

(C) 2008 Copyright the Authors

Journal compilation (C) 2008 Wiley Periodicals, Inc. 
than that of older citizens (Highton \& Wolfinger, 2001). For example, in the 1996 and 2000 presidential elections, only about one third of all eligible voters aged 18-24 cast ballots (Center for Information \& Research on Civic Learning and Engagement [CIRCLE], 2005). Further, just $47 \%$ of young adults voted in the 2004 presidential election, compared to $55 \%$ of those aged $24-55$ and $72 \%$ of those aged 55 and older (U.S. Census Bureau, 2004). Indeed, Rosenstone, and Hansen (1993) found strong evidence for age as an important determinant of voting behavior, with young adults voting less than other age cohorts (e.g., the middle aged).

Increasing voting participation among young adults is of great consequence for two reasons. First, research has suggested that early political participation predicts future electoral involvement (i.e., voting is "habit forming"; see Green \& Shachar, 2000; Matsusaka \& Palda, 1999). Therefore, increasing turnout at a young age can potentially increase overall turnout in the future. Second, when large segments of the population do not vote, the democratic system itself is weakened. Indeed, young voters - as with all groups that do not vote consistently - have unequal influence in the electoral system (Lijphart, 1997). Thus, increasing turnout among young adults can result in elected officials attending to the needs of this population (e.g., college loan funding), rendering the democratic system better able to live up to its principles.

A number of large qualitative surveys (e.g., Third Millennium Survey: Freyman \& McGoldrick, 2000; National Association of Secretaries of State survey, 1998) as well as smaller, quantitative studies (e.g., Highton \& Wolfinger, 2001) have explored the reasons for low voter turnout among young adults. Unfavorable political attitudes are often cited as an explanation for low voting rates among this population. For example, trust in government (Abramson \& Aldrich, 1982; Plutzer, 2002), internal political efficacy (i.e., beliefs about understanding and influencing politics; Knack, 1992), and external efficacy (i.e., beliefs about the responsiveness of government; Hetherington, 1998; Rosenstone \& Hansen, 1993) are cited as reasons why young adults do not vote. Although investigating political attitudes is important for understanding the phenomenon of low turnout among this population, it does not provide a clear framework for increasing political participation of young adults.

Using theory-driven models, which specify a set of specified constructs as determinants of behavior, to predict voting can provide a more comprehensive understanding of low voter turnout, as well as a framework for increasing voting behavior (e.g., Ajzen, Timco, \& White, 1982; Netemeyer \& Burton, 1990). Given the low voter turnout of young adults, there is a need for a greater understanding of the factors that lead young adults to vote. As behavioral models provide a systematic analysis of the conceptual factors that lead to a 
given behavior, behavioral models provide a framework for creating interventions that can be applied in a variety of settings. The present work contrasts the utility of three behavioral models to the behavior of young adult voting.

\section{Behavioral Models}

Two of the most influential models for predicting behavior are the theory of reasoned action (TRA; Ajzen \& Fishbein, 1980) and the theory of planned behavior (TPB; Ajzen, 1985; Ajzen \& Fishbein, 2005). Both models posit that intentions predict behavior and specify a set of variables that are assumed to affect the intention to behave. Despite the application of the two models to a substantial number of behaviors and populations, as well as to voting behavior (e.g., Ajzen et al., 1982; Netemeyer \& Burton, 1990), relatively few studies have used attitude-behavior models (e.g., TRA) to explore young adults' voting behavior (for an exception, see Ajzen et al., 1982).

Building on the TRA and the TPB, Fisher and Fisher (1992) developed another model that explains behavior via the constructs of information, motivation, and behavioral skills (IMB). Specifically, the model posits that information and motivation work primarily through behavioral skills to influence behavior. The strength of this model is in its ability to serve as a tool for developing programs of behavioral change. Indeed, there is considerable support for the ability of IMB methods to change health-related behaviors (Fisher \& Fisher, 2000). However, research has not yet examined the components of the IMB with respect to voting behavior.

Increasing young adults' voting behavior can potentially increase voter turnout in the future, as well as strengthen the current democratic system. In light of the ability of behavioral models to predict behavior and produce behavioral change, as well as the lack of application of these models to young adults' voting behavior, the present research explores the utility of the components in the three models to predict young adults' voting behavior. Each of the models will be outlined, as well as predictions for the present studies.

\section{Theories of Reasoned Action and Planned Behavior}

The TRA has been used extensively across the social sciences to examine prediction of behavior. According to the TRA, behavioral intention is an antecedent to behavior, and intentions are determined by two factors: One is an individual's attitude toward performing the behavior; that is, how negative or positive an individual feels toward the behavior. For example, with respect to voting behavior, a positive attitude would mean an individual feels positive 
toward the behavior of voting. The other antecedent to behavior specified by the TRA is subjective norms, or an individual's perception of whether others think the behavior is important (Ajzen \& Fishbein, 1980). For example, if someone perceives that important others (e.g., family, friends) believe that voting is unimportant, their perception will be that the norm is not to vote.

The TPB is an extension of the TRA that incorporates an individual's perception of the ease with which the behavior can be performed (Ajzen, 1985). For example, if a person feels that there are many obstacles that prevent him or her from voting, such as difficulty traveling to the voting site, his or her perceived behavioral control (PBC) would be low. Thus, rather than measuring one's sense of having a say in government (i.e., internal political efficacy), PBC assesses the extent to which a person perceives that he or she has complete control over engaging in the behavior, or voting in the present work. The TPB adds PBC as an antecedent to behavioral intentions, as well as to behavior. Over 35 years of research has provided strong support for the predictive validity of the two models (Albarracin, Johnson, Fishbein, \& Muellerleile, 2001; Armitage \& Conner, 2001; Conner \& Armitage, 1998; Hagger, Chatzisarantis, \& Biddle, 2002; Sheeran \& Taylor, 1999; Sheppard, Hartwick, \& Warshaw, 1988).

With respect to voting behavior, there is support for the predictive validity of both models (Ajzen et al., 1982; Bowman \& Fishbein, 1978; Netemeyer \& Burton, 1990; Singh, Leong, Tan, \& Wong, 1995). For example, Ajzen et al. found support for the ability of the TRA to explain substantial variance of voting among young adults. Specifically, participants were given a questionnaire assessing the components of the TRA, attitudes, and subjective norms toward voting in the 1980 presidential election (as well as the intention to vote in the election) prior to the 1980 election, and then were asked to report their voting behavior 2 weeks after the election. The TRA components explained $52 \%$ of the variance for the intention to vote and $31 \%$ of the variance for voting behavior.

However, Ajzen et al.'s (1982) study is one of the few to use participants under the age of 24 exclusively to test the components of the TRA and the TPB in the voting domain. Thus, there is little research examining the predictive validity of either of the models for the voting behavior of young adults. The present research provides a direct empirical test of the two models for voting behavior among this population.

\section{Information-Motivation-Behavioral Skills Model}

The literature on the voting behavior of adults, as well as young adults, demonstrates the importance of information, motivation, and behavioral 
skills to voting behavior. For example, individuals who are more informed about politics (Teixeira, 1992), who are more personally invested (Rosenstone \& Hansen, 1993), and who have a greater number of resources and skills (Verba, Schlozman, \& Brady, 1995) are all more likely to vote. Although research has suggested the importance of each factor separately, no empirical participation model has integrated the three factors.

The information-motivation-behavioral skills (IMB) model (Fisher \& Fisher, 1992, 1993) provides a useful framework for incorporating the three components. The IMB model posits that performance of a given behavior is based on an individual's information, motivation, and behavioral skills related to the behavior. The model conceptualizes the psychological determinants needed to promote behavior and provides a general framework for how to increase the specific behavior in targeted populations.

According to the IMB model, information is an initial prerequisite to performing a given behavior. For example, in order to vote in a particular election, it would be necessary to possess information about how to vote, as well information about the candidates.

Motivation to engage in a behavior is a second prerequisite for performing a given behavior and is theorized to include both personal motivation (i.e., attitudes toward performing the behavior), as well as social motivation (i.e., perceived social support for engaging in the behavior). Thus, the IMB model suggests that whether an individual is motivated to vote is determined not only by their own personal feelings regarding whether voting is a good thing to do, but also whether friends and other important referents provide social support for voting behavior.

Finally, according to the IMB model, behavioral skills are a third prerequisite to performing a given behavior. Specifically, the model posits that an individual's sense of efficacy regarding the behavioral skills necessary to perform the behavior help to determine whether the individual engages in the behavior. Thus, an individual would need to perceive that he or she has the behavioral skills necessary to vote. In sum, according to the IMB model, the extent to which individuals will vote is determined by whether they are well informed and motivated to act, and whether they perceive that they have the behavioral skills necessary to vote (Fisher \& Fisher, 1992).

The IMB model has been used primarily as a model for HIV risk reduction, and there is strong support for the efficacy of the model in this domain (e.g., Carey et al., 1997; Fisher \& Fisher, 2000; Fisher, Fisher, Misovich, Kimble, \& Malloy, 1996). In addition, although the IMB model typically has been used in the area of HIV, it has been theorized that the model is applicable to behaviors outside of the HIV domain (Fisher \& Fisher, 1996, 2000). Indeed, the IMB constructs have been shown to change (via intervention) successfully and to predict a number of non-HIV-risk-reduction behaviors, 
including breast self-examination among women (Misovich, Martinez, Fisher, Bryan, \& Catapano, 2003), adolescent smoking behavior (Botvin, Dusenbury, Baker, James-Ortiz, \& Kerner, 1989), and oral rehydration in developing countries (Foote et al., 1985). Nevertheless, despite the model's success, there has been no research examining how well the components of the IMB model predict voting behavior.

Conceptually, the IMB shares similar constructs with the TRA and the TPB. That is, in all three models, attitudes are considered a prerequisite for behavior. In the IMB model, however, attitudes are conceptualized as personal motivation. The IMB model also draws on the TRA and the TPB for its conceptualization of social motivation (Fisher \& Fisher, 1992). However, the two constructs are distinct to the extent that subjective norms measure perceptions of others' behavior, and social motivation assesses social support for engaging in a given behavior. Nonetheless, it would be expected that social motivation and subjective norms would have a high positive correlation. Thus, the IMB adds one similar construct (i.e., social motivation) and two unique constructs (i.e., information and behavioral skills) to the TRA and the TPB.

The three models have not been contrasted empirically. However, in a comparative review, Fisher and Fisher (2000) found evidence that the components of the IMB model often explain an equal or greater amount of variance, relative to the TRA and the TPB, for HIV-preventive behaviors (e.g., condom use). Thus, the review suggests that the components that the IMB model adds to the TRA and the TPB - information, social motivation, and behavioral skills - explain unique variance for health-related behaviors. The present research examines whether the components suggested by the IMB model can also explain variance unique to the prediction of voting behavior of young adults, over and above the TRA and the TPB.

\section{The Present Research}

Young adults consistently vote less than do other age groups in presidential elections (Highton \& Wolfinger, 2001). Given the ability of the established methods of TRA, TPB, and IMB to increase behaviors, identifying which of the three models best predicts young adult voting can help to provide not only a greater understanding of the factors that lead to young adult voting, but also a framework for how to create interventions in the future. The present research, therefore, compares the TRA, TPB, and IMB models for intention to vote (Study 1) and voting behavior (Study 2) in the 2004 presidential election. The goal of the present set of studies is to examine whether the components of the IMB model explain variance unique to the 
prediction of voting behavior of young adults, over and above the TRA and the TPB, and thereby identify the factors that lead young adults to vote. ${ }^{2}$

To explore the predictive utility of the three models, the intention to vote and voting behavior was assessed during the 2004 presidential election. Prior to the November 2004 election, participants were given a questionnaire assessing the components of the three models, as well as additional political attitude variables (e.g., trust in government), and intention to vote in the 2004 presidential election. Shortly after the election, a separate sample of participants was given a questionnaire assessing the components of the three models, political attitude variables, and voting behavior.

A hierarchical regression analysis allows for behavioral model comparison. Therefore, to assess the predictive utility of each model, over and above the political attitude variables, hierarchical regressions were conducted. As past research has already demonstrated the utility of the TRA and TPB in the voting domain, the components of IMB model were entered last. To provide a stronger test of the unique variance explained by the three models, political attitude variables that past research has shown to be important to voting (e.g., political efficacy, trust in government) were entered at Step 1 of the regression. The components of the three models were then entered. Thus, the components of the TRA were entered at Step 2; the components of the TPB at Step 3; and finally, the components of the IMB model at Step 4. Thus, the components of the TRA, TPB, and IMB were entered at each successive step to provide a test of the unique variance the components of each model added to the prediction of the intention to vote and voting behavior. ${ }^{3}$

Consistent with past research (Armitage \& Conner, 2001), it is predicted that adding perceived behavioral control to the components of the TRA will significantly increase the amount of variance explained. Further, based on previous research illustrating the predictive utility of the IMB model (Fisher \& Fisher, 2000) and research suggesting the importance of

${ }^{2}$ The cross-sectional design of the present studies suggests that caution should be exercised in interpreting the word prediction. That is, for each study, all data were collected at the same time point. However, the present results are informative because cross-sectional designs can help to discover the presence, as well as strength of association between a set of specified variables. Therefore, it is appropriate for the present research question.

${ }^{3}$ It is acknowledged that a variety of individual-level factors (e.g., socioeconomic status, parental education) may influence voter turnout among young adults (Wolfinger \& Rosenstone, 1980). However, in the present sample, there was relatively little variance in terms of socioeconomic status. Further, research has found that many of the demographic and socioeconomic variables that are associated with general population voting are not primary determinants of young adult voting (Niemi \& Hanmer, 2006). For example, Niemi and Hanmer found little or no effect of age, employment, income, and race on voter turnout. Therefore, the present research seeks to examine trust in government and political efficacy because of the likelihood of variance and evidence suggesting a strong relation between these variables and electoral involvement in young adults (Rosenstone \& Hansen, 1993). 
information, motivation, and skills to voter turnout (Rosenstone \& Hansen, 1993; Teixeira, 1992; Verba et al., 1995), it is predicted that the components of the IMB model will significantly increase the amount of variance explained, over and above the TRA and the TPB.

\section{Study 1: Predicting Intention to Vote}

\section{Method}

\section{Participants}

Participants were 236 undergraduates (145 female, 91 male) at a large northeastern university who participated in Study 1 for credit toward their introductory psychology course. The participants ranged in age from 18 to 24 years. With regard to ethnicity, $83.2 \%$ of the sample was White, $6.0 \%$ was Black, $1.7 \%$ was Latino, and $9.1 \%$ indicated they were biracial or "Other."

\section{Procedure}

All data were collected in Fall 2004, prior to Election Day in November. Each participant was given a single questionnaire measuring intention to vote; the components of the TRA, the TPB, and the IMB models; as well as trust in government, internal political efficacy, and external political efficacy. Items for each of the constructs for the three models, as well as intention to vote were interspersed.

\section{Measures}

Theories of reasoned action and planned behavior. The items and measures used to assess attitudes, subjective norms, and $\mathrm{PBC}$ were based on previous work exploring the TRA and TPB in the voting domain (Ajzen et al., 1982; Netemeyer \& Burton, 1990).

Attitudes. Attitudes toward voting in the 2004 presidential election were measured using a three-item semantic-differential scale. The items were introduced with the statement "Voting in the 2004 presidential election would be ..." and were followed by the anchors good-bad, harmful-beneficial, and rewarding-punishing. Items were rated on a 7-point scale ranging from 1 (strongly disagree) to 7 (strongly agree; $\alpha=.73$ ).

Subjective norms. Consistent with TRA guidelines, subjective norms were measured by multiplying an item assessing motivation to comply ("Generally 
speaking, how much do you want to do what your family and friends think you should do?") with an item measuring perceived norms ("Most people who are important to me think I should vote in the 2004 presidential election"). Both items were measured on a 7-point scale ranging from 1 (not at all) to 7 (very much).

Perceived behavioral control. The additional component of $\mathrm{PBC}$, postulated by the TPB, was measured using the following three items: "I have control over whether I will be able to vote in the 2004 presidential election"; "How hard would it be for you to vote in the 2004 presidential election?"; "How hard would it be to find solutions to any obstacles that would prevent you from getting to the polling place on Election Day?" Items were rated on a 5-point scale ranging from 1 (not at all/not at all hard) to 5 (very much/very hard; $\alpha=.86)$.

Information, motivation, and behavioral skills. The items and measures used to assess information, motivation, and behavioral skills are based on previous work, but were tailored to behavior in the voting domain (Misovich et al., 2003). The IMB model posits that information related to enactment of the behavior is an initial prerequisite of engaging in behavior (Fisher \& Fisher, 1992).

Information was assessed by summing the number of correct answers to 15 questions that assess the degree to which participants correctly answered questions about general information needed to enact the behavior of voting (e.g., "In the voting booth, if a lever system is used, the name of all party candidates is assigned to a particular lever"; True, False, or I don't know), the candidates (e.g., "John Kerry is a Republican"; True, False, or I don't know), the election process (e.g., "Presidential elections are held every . .."; 6 years, 4 years, etc.), and the national political context (e.g., "Which party is more conservative than the other on the national level?"; Democrats, Republicans, etc.; $M=10.45, S D=2.34$ ).

The IMB model suggests that both personal and social motivation are associated with performing a behavior (Fisher \& Fisher, 1992). As the personal motivation component is conceptualized as personal attitudes - and was measured identically across the three models - the present research explores the unique contribution of social motivation.

Social motivation is conceptualized to be similar, but not identical to the subjective norms construct of the TRA and TPB (Fisher \& Fisher, 1992). Specifically, whereas subjective norms assess perceptions of how normative a given behavior is, social motivation assesses social support for enacting a given behavior. In the present study, it was measured using the following three items: "Most people who are important to me think I should vote"; "Most people who are important to me think I should vote in the 2004 presidential election"; and "My friends and family think I should vote in the 
2004 presidential election." The items were rated on a 7-point scale ranging from 1 (strongly disagree) to 7 (strongly agree; $\alpha=.96$ ).

Behavioral skills (i.e., perceived self-efficacy with respect to the skills needed to vote) were examined using three items assessing the extent to which participants believed it was easy or difficult to perform behaviors related to voting. Specifically, the following three items were used to examine behavioral skills: "How hard would it be for you to keep track of where politicians stand on issues relevant to you?"; "How hard would it be for you to find out where to vote on Election Day?"; and "How hard would it be for you to learn the skills needed to vote in a voting booth?" The items were rated on a 5-point scale ranging from 1 (very hard to do) to 5 (very easy to do; $\alpha=.73$ ).

Trust in government, internal political efficacy, and external political efficacy. Predictive validity of the three models was assessed over and above the explanatory power of three constructs that have been shown to be associated with voting behavior. Those constructs are trust in government, internal political efficacy, and external political efficacy (Wolfinger \& Rosenstone, 1980; Rosenstone \& Hansen, 1993).

Trust in government was measured using the standard Current Population Survey items (American National Election Studies, 2005; U.S. Census Bureau, 2004). Participants responded to the item "How much of the time do you think you can trust the government in Washington to do what is right?" on a 5-point scale ranging from 1 (none of the time) to 5 (just about always). The second item asked "Would you say the government is pretty much run by a few big interests looking out for themselves or that it is run for the benefit of all the people?" The item was rated on a 5-point scale ranging from 1 (benefit of all) to 5 (few big interests). Finally, participants responded to the item "Do you think quite a few of the people running the government are dishonest, not many are, or do you think hardly any of them are dishonest?" on a 5-point scale ranging from 1 (quite a few) to 5 (hardly any; $\alpha=.71$; $M=2.78, S D=0.71)$.

Internal political efficacy was measured using three items based on previous work (e.g., Morrell, 2003). The items are "People like me don't have any say about what the government does," "It is only wishful thinking to believe that one can really influence what happens in society at large," and "The way people vote is the main thing that decides how things are run in this country." The items were rated on a 7-point scale ranging from 1 (strongly disagree) to 7 (strongly agree; $\alpha=.75 ; M=3.63, S D=1.33$ ).

External political efficacy was measured using three items based on previous work (e.g., Craig \& Maggiotto, 1982). The items are "I don't think public officials care much what people like me think," "Generally speaking, those we elect to Congress in Washington lose touch with the people pretty quickly," and "The people in Washington, D.C. are out of touch with the rest 
of the country." The items were rated on a 7-point scale ranging from 1 (strongly disagree) to 7 (strongly agree; $\alpha=.77 ; M=4.19, S D=1.22$ ).

\section{Dependent Variable}

The dependent variable - intention to vote in the 2004 presidential election -was measured using the following items: "So far as I know, I expect to vote in the national election this coming November," "I plan to vote in the 2004 presidential election," and "I intend to vote in the 2004 presidential election." The items were rated on a 7-point scale ranging from 1 (strongly disagree) to 7 (strongly agree; $\alpha=.95 ; M=5.95, S D=1.83$ ). These items were based on previous work (e.g., Bowman \& Fishbein, 1978).

\section{Results}

To assess the predictive validity of the components of the three models over and above trust in government, internal political efficacy, and external political efficacy, a hierarchical regression was performed (see Table 1 for correlations). In Step 1 of the regression, the political attitude variables were entered; followed by the TRA variables at Step 2; followed by the addition of $\mathrm{PBC}$ at Step 3; and finally, the information, social motivation, and behavioral skills variables of the IMB model at Step 4 (see Table 2 for full results). The PBC and IMB variables were entered at Steps 3 and 4, respectively, to assess the unique contribution of the components over and above the TRA. Thus, Step 2 assessed the contribution of attitudes and subjective norms, and Step 3 assessed the contribution of PBC. Finally, Step 4 assessed the contribution of information, social motivation, and behavioral skills.

At Step 2 of the model, both TRA variables - attitudes toward voting in the 2004 presidential election $(\beta=.42), t(231)=7.26, p<.01$; and subjective norms $(\beta=.20), t(231)=3.55, p<.001$ - were significant predictors of intention to vote $\left(R^{2}=.27\right), F(5,231)=17.16, p<.001$. Consistent with past research (Ajzen \& Madden, 1986), the addition of the TPB variable of PBC $(\beta=.33), t(230)=6.14, p<.001$, improved the predictive validity of the model over and above the TRA $\left(R^{2} \Delta=.10\right), F_{\text {change }}(1,230)=37.69, p<.001$.

Finally, the present results suggest that the addition of the IMB components improved the predictive validity of the model. More specifically, at the final step of the regression, in addition to $\mathrm{PBC}(\beta=.23), t(227)=4.42$, $p<.001$; information $(\beta=.10), t(227)=2.34, p<.05$; social motivation $(\beta=.51), t(227)=8.87, p<.001$; and behavioral skills $(\beta=.18), t(227)=3.62$, $p<.001$, were the only significant predictors of intention to vote in the 2004 presidential election $\left(R^{2} \Delta=.21\right), F_{\text {change }}(3,227)=38.23, p<.001$. 


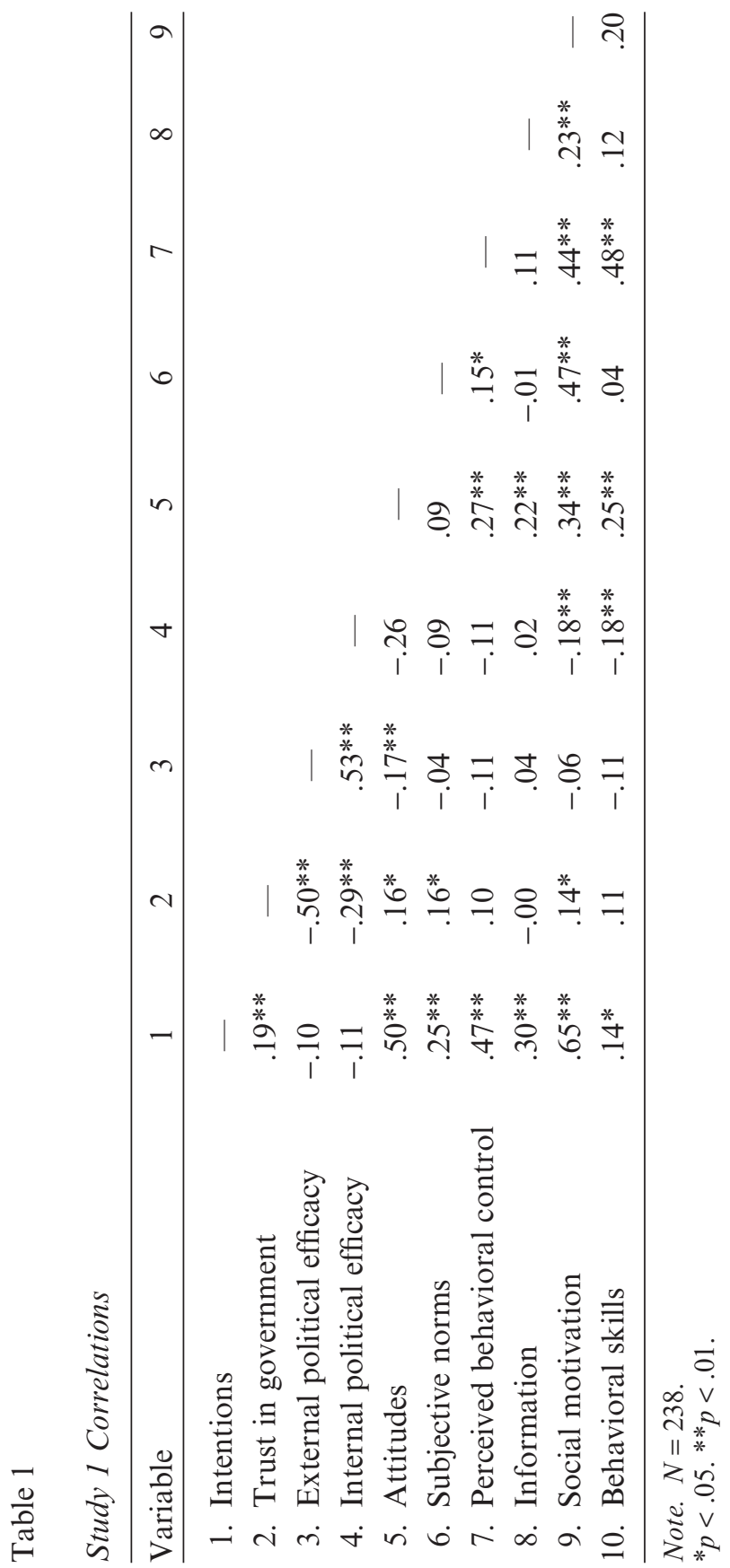


Table 2

Study 1 Voting Intentions: Hierarchical Regression Results

\begin{tabular}{lrrll}
\hline & $\beta$ & $t$ & $p$ & $R^{2}$ \\
\hline Step 1: Political attitude variables & & & & .05 \\
$\quad$ Trust in government & .19 & 2.67 & $.00^{* * *}$ & \\
External political efficacy & .08 & 1.02 & .30 & \\
$\quad$ Internal political efficacy & .02 & 0.27 & .78 & \\
Step 2: Theory of reasoned action & & & & $.27^{* * *}$ \\
Trust in government & .12 & 1.81 & .07 & \\
External political efficacy & .06 & 0.88 & .38 & \\
Internal political efficacy & .09 & 1.50 & .13 & \\
Attitudes & .42 & 7.26 & $.00^{* * *}$ & \\
Subjective norms & .20 & 3.55 & $.00^{* * *}$ & \\
Step 3: Theory of planned behavior & & & & $.44^{* * *}$ \\
Trust in government & .11 & 1.85 & .06 & \\
External political efficacy & .08 & 1.20 & .23 & \\
Internal political efficacy & .08 & 1.46 & .14 & \\
Attitudes & .34 & 6.22 & $.00^{* * *}$ & \\
Subjective norms & .16 & 2.98 & $.00^{* *}$ & \\
Perceived behavioral control & .33 & 6.14 & $.00^{* * *}$ & \\
Step 4: Information-Motivation- & & & & $.59 * * *$ \\
Behavioral Skills model & & & & \\
Trust in government & .09 & 1.84 & .06 & \\
External political efficacy & .00 & 0.13 & .89 & \\
Internal political efficacy & .07 & 1.45 & .15 & \\
Attitudes & -.12 & -0.53 & .59 & \\
Subjective norms & -.02 & -0.58 & .56 & \\
Perceived behavioral control & .23 & 4.42 & $.00^{* * *}$ & \\
Information & .10 & 2.34 & $.02^{* *}$ & \\
Social motivation & .51 & 8.87 & $.00^{* * *}$ & \\
Behavioral skills & .18 & 3.62 & $.00^{* * *}$ & \\
\hline
\end{tabular}

${ }^{*} p<.05 .{ }^{* *} p<.01 .{ }^{* * *} p<.001$. 


\section{Discussion}

The results of Study 1 provide initial empirical support for the utility of the components of the IMB model for predicting intention to vote, as well as the unique contribution of the IMB components over and above the TRA and TPB. The present results suggest that the components of the IMB and TPB models are significantly associated with intention to vote. Indeed, in the final model, PBC, information, social motivation, and behavioral skills were significantly related to intention to vote. Consistent with the hypotheses, the constructs of the TPB improved the predictive ability of the model over and above the TRA constructs, and the IMB constructs improved the predictive ability of the model over above the TRA and TPB constructs. Study 1 also provides initial evidence of the utility of the IMB model in a non-health domain.

Intention to vote is often highly correlated with voting behavior (Ajzen et al., 1982), and thus provides a strong test of the models with respect to voting behavior. However, to provide an additional test of the models in the voting domain, Study 2 tests the utility of the models for self-reported voting behavior for the 2004 presidential election. Specifically, Study 2 uses a logistic regression to compare and contrast the components of the three behavioral models.

\section{Study 2: Prediction of Voting Behavior}

\section{Method}

\section{Participants}

Participants were 166 undergraduates (105 female, 61 male) who participated in Study 2 for credit toward their introductory psychology course. The participants ranged in age from 18 to 24 years. With regard to ethnicity, $80 \%$ of the sample was White, $6 \%$ was Latino(a), $3 \%$ was Black, $1 \%$ was Native American, and $11 \%$ indicated that they were biracial or "Other."

\section{Procedure}

All data were collected after the 2004 presidential election in November 2004. Each participant was given a single questionnaire that measures the components of the TRA, TPB, and the IMB model; as well as trust in government, internal political efficacy, and external political efficacy. Once again, the items for the constructs of the three models were interspersed. 


\section{Measures}

All of the Study 2 measures were identical to those in Study 1. Thus, trust in government $(\alpha=.78)$, internal political efficacy $(\alpha=.76)$, external political efficacy $(\alpha=.73)$, attitudes $(\alpha=.83)$, subjective norms, perceived behavioral control $(\alpha=.73)$, information, social motivation $(\alpha=.95)$, and behavioral skills $(\alpha=.73)$ were all measured.

\section{Dependent Variable}

The dependent variable — voting behavior — was measured using a single item. Participants responded to the question "Did you vote in the 2004 presidential election?" by circling either No (coded as 0 ) or Yes (coded as 1). This item was based on past research assessing self-reported voting behavior (e.g., American National Election Studies, 2005; Bassili, 1993).

\section{Results}

To assess the predictive validity of the components of the IMB modelover and above trust in government, internal political efficacy, external political efficacy, and the components of the TRA and TPB - a hierarchical logistic regression was performed (see Table 3 for correlations). Specifically, a logistic regression was used to examine how the constructs of the TRA, TPB, and IMB model, as well as political attitude variables affected likelihood of voting in the 2004 presidential election.

The variables entered at each step were identical to those in Study 1. Thus, the political attitude variables were entered on Step 1 of the regression; followed by the TRA variables at Step 2; followed by addition of the PBC variable at Step 3; and finally, the information, social motivation, and behavioral skills variables of the IMB model at Step 4.

The deviance for the null model $\left(D_{0}\right)$ was 198.498 , and the deviance for the political attitudes Block I model $\left(D_{m 1}\right)$ was 182.012. The chi-square difference $(G)$ between the null model and the explanatory block model was as follows: $\chi_{\text {diff. }}^{2}(3, N=167)=16.48, p<.01$. The chi-square difference between the political attitudes model and the TRA model $\left(D_{m 2}\right)$ was as follows: $\chi^{2}$ diff. $(2$, $N=167)=7.89, p<.05$, demonstrating that the TRA variables significantly improved the fit of the model. The chi-square difference between the TRA model $\left(D_{m 2}\right)$ and the TPB model $\left(D_{m 3}\right)$ was as follows: $\chi_{\text {diff. }}^{2}(1$, $N=167)=10.78, p<.01$. Thus, the model with PBC included significantly improved the fit of the model. Finally, the chi-square difference between the 


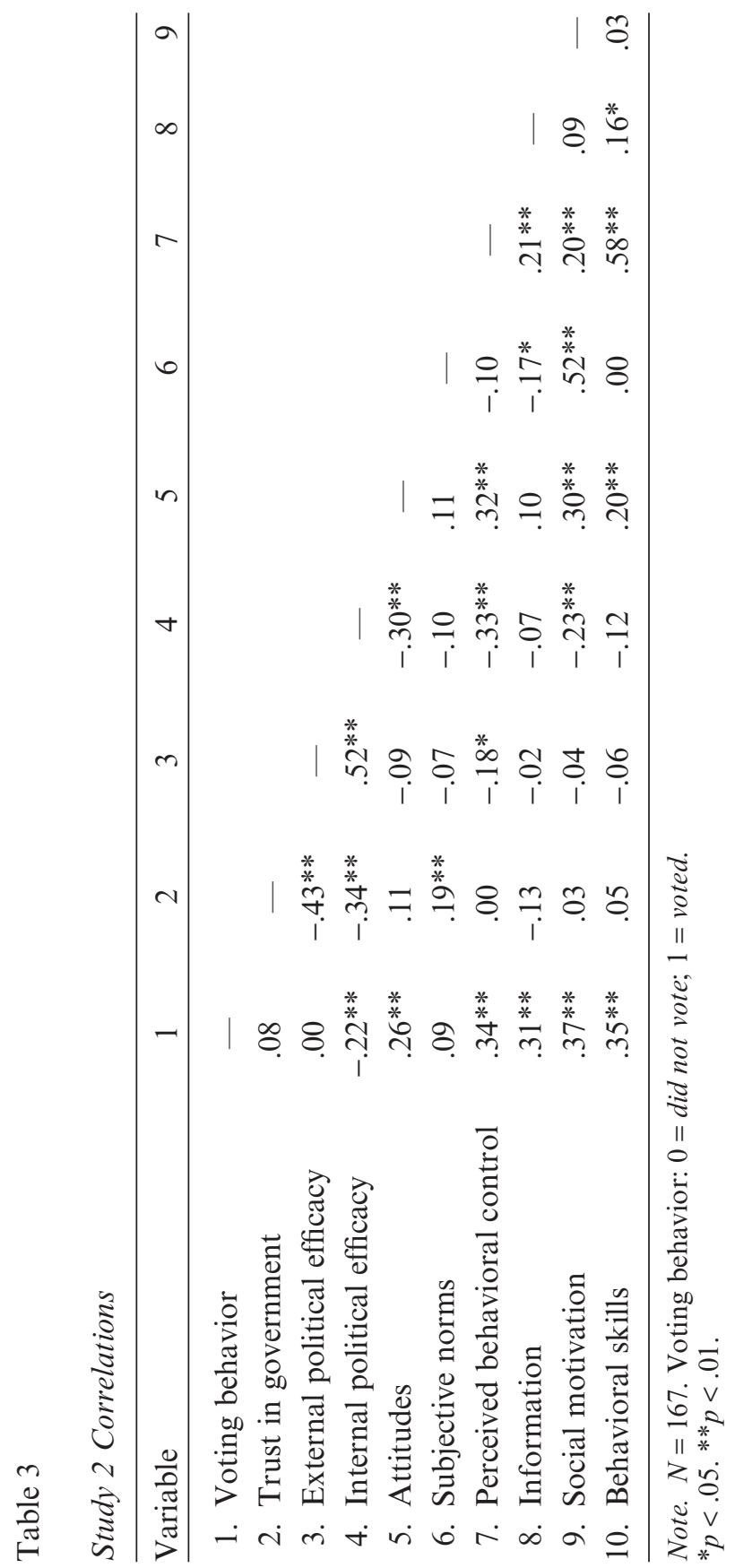


TPB model and the IMB model was as follows: $\chi^{2}$ diff. $(2, N=167)=18.62$, $p<.001$. Thus, the full model including the IMB variables significantly improved the fit of the model.

The results of the Hosmer and Lemeshow test for the blocks are as follows: political attitudes model, $\mathrm{C}$-hat $=6.80, p=.55$; TRA model, C-hat $=7.41, p=.49 ; \quad$ TPB,$\quad$-hat $=6.69, p=.57$; and IMB model, $\mathrm{C}$-hat $=10.15, p=.25$. The nonsignificant $p$ values of all of the models suggest that the data accurately represent the data.

The likelihood ratio $R^{2}$ results for the models are as follows: political attitudes model $=.08$; TRA $=.04$; TPB $=.06$; and IMB $=.11$. Thus, the likelihood ratio $R^{2}$ results suggest that the political attitude model accounted for an $8 \%$ reduction in deviance from the null model; the TRA model accounted for a $4 \%$ reduction in deviance from the null model; the TPB model accounted for a $6 \%$ reduction in deviance from the null model; and the IMB accounted for an $11 \%$ reduction in deviance from the null model.

The classification table results for each of the models are as follows: The political attitudes model classified $71 \%$ of cases correctly; the TRA model classified $76 \%$ of cases correctly; the TPB model classified $77 \%$ of cases correctly; and the full model with the IMB variables classified $77 \%$ of cases correctly. However, the $\tau_{\mathrm{p}}$ statistic, which adjusts for the base rate of correct classification, suggests that the political attitudes model reduced classification error by $27 \%$, the TRA model reduced classification error by $40 \%$, the TPB reduced classification error by $44 \%$, and the full model including the IMB variables reduced classification error by $45 \%$.

The final logistic regression model suggests that PBC, information, and social motivation are the critical variables distinguishing those who are likely to vote and those who are less likely to vote (see Table 4). Specifically, people who perceive that they have high behavioral control over voting are 1.66 times as likely to vote as those who have lower levels of PBC. Similarly, people who have high social motivation - that is, those who have social support from family and friends - are 1.62 times as likely to vote, compared to individuals who do not have family and friends who support voting. Finally, the odds that an individual will vote increase by 1.39 the more knowledge the individual has about the voting process, the candidates, and information needed to make an informed decision.

\section{Discussion}

Consistent with Study 1, Study 2 found that the constructs of the IMB model significantly predicted voting behavior, a nonhealth behavior, as well as explained variance unique to the prediction of the behavior, over and 


\section{Table 4}

Study 2 Voting Behavior: Logistic Regression Results

\begin{tabular}{|c|c|c|c|c|c|c|}
\hline & \multirow[b]{2}{*}{$B$} & \multirow[b]{2}{*}{ Wald } & \multirow[b]{2}{*}{$p$} & \multirow[b]{2}{*}{$\operatorname{Exp}(B)$} & \multicolumn{2}{|c|}{$95 \% \mathrm{CI}$} \\
\hline & & & & & Lower & Upper \\
\hline \multicolumn{7}{|l|}{ Step 1: Political attitude variables } \\
\hline Trust in government & -.462 & 3.53 & .06 & 0.63 & 0.39 & 1.02 \\
\hline External political efficacy & .277 & 1.94 & .16 & 1.31 & 0.89 & 1.94 \\
\hline Internal political efficacy & -.650 & 13.29 & $.00 * * *$ & .522 & 0.37 & 0.74 \\
\hline Constant & 3.63 & 7.64 & .00 & 37.98 & & \\
\hline \multicolumn{7}{|l|}{ Step 2: Theory of reasoned action } \\
\hline Trust in government & -.536 & 4.37 & $.03^{*}$ & 0.59 & 0.35 & 0.97 \\
\hline External political efficacy & .247 & 1.45 & .22 & 1.28 & 0.86 & 1.91 \\
\hline Internal political efficacy & -.556 & 9.00 & $.00^{* *}$ & 0.57 & 0.40 & 0.83 \\
\hline Attitudes & .466 & 5.89 & $.01^{*}$ & 1.59 & 1.09 & 2.32 \\
\hline Subjective norms & .019 & 1.20 & .27 & 1.02 & 0.99 & 1.05 \\
\hline Constant & .344 & 0.04 & .84 & 1.41 & & \\
\hline \multicolumn{7}{|c|}{ Step 3: Theory of planned behavior } \\
\hline Trust in government & -.456 & 2.92 & .08 & 0.63 & 0.38 & 1.06 \\
\hline External political efficacy & .299 & 2.02 & .15 & 1.35 & 0.89 & 2.04 \\
\hline Internal political efficacy & -.416 & 4.91 & $.02 *$ & 0.66 & 0.46 & 0.95 \\
\hline Attitudes & .311 & 2.40 & .12 & 1.36 & 0.92 & 2.02 \\
\hline Subjective norms & .033 & 2.88 & .08 & 1.03 & 1.00 & 1.07 \\
\hline Perceived behavioral control & .592 & 10.34 & $.00^{* *}$ & 1.80 & 1.26 & 2.59 \\
\hline Constant & -3.26 & 2.25 & .13 & 0.04 & & \\
\hline \multicolumn{7}{|l|}{$\begin{array}{l}\text { Step 4: Information-Motivation- } \\
\text { Behavioral Skills model }\end{array}$} \\
\hline Trust in government & -.307 & 1.08 & .29 & 0.74 & 0.41 & 1.31 \\
\hline External political efficacy & .291 & 1.63 & .20 & 1.33 & 0.86 & 2.09 \\
\hline Internal political efficacy & -.362 & 3.21 & .07 & 0.70 & 0.47 & 1.03 \\
\hline Attitudes & .188 & 0.77 & .38 & 1.20 & 0.79 & 1.83 \\
\hline Subjective norms & .005 & 0.04 & .85 & 1.00 & 0.95 & 1.05 \\
\hline Perceived behavioral control & .507 & 6.57 & $.01^{*}$ & 1.66 & 1.12 & 2.44 \\
\hline Information & .329 & 8.48 & $.00^{* *}$ & 1.39 & 1.11 & 1.73 \\
\hline Social motivation & .483 & 5.95 & $.01^{*}$ & 1.62 & 1.10 & 2.38 \\
\hline Constant & -7.55 & 7.90 & $.00 * *$ & .001 & & \\
\hline
\end{tabular}

Note. $n=167$. Model fit criteria: $-2 \log$ likelihood $=144.708 ; \chi^{2}(8, N=167)=10.15, p=.254$; Cox \& Snell's $R^{2}=.27$; Nagelkerke's $R^{2}=.39$. The behavioral skills variable was excluded from the final model as a result of inclusion criteria.

${ }^{*} p<.05 .{ }^{* *} p<.01 .{ }^{* * *} p<.001$. 
above the TRA and TPB constructs. Study 2 found, consistent with Study 1, that the addition of the $\mathrm{PBC}$ variable improved the prediction of voting behavior, over and above the TRA, a finding that is consistent with past research (Ajzen et al., 1982).

Study 2, similar to Study 1, found that the constructs of the IMB model significantly improved prediction of voting behavior. Indeed, Study 2 found that information and social motivation were significant predictors of voting behavior, such that the more information and social motivation a person had, the more likely that person was to vote. The present research provides initial evidence of the predictive validity of the IMB constructs to explain voter turnout among young adults.

\section{General Discussion}

The present research examined whether the components specified by the IMB model explain unique variance in young adults' voting behavior, over and above the TRA and the TPB. As expected, and consistent with the high predictive utility of the IMB model in the health domain, the two studies showed the unique contribution of the components of the IMB model, over and above the components of the TRA and the TPB.

Given past support for the efficacy of the IMB model in changing behaviors (Fisher \& Fisher, 2000) - as well as past research demonstrating the importance of information, motivation, and behavioral skills to voter turnout among young adults (Rosenstone \& Hansen, 1993; Strate, Parrish, Elder, \& Ford, 1989; Verba et al., 1995) - the present results suggest a number of practical strategies for programs designed to increase voter turnout among young adults. Specifically, these types of programs should (a) increase the perception that voting is under young adults' control; (b) provide information regarding how and where to vote, information about the candidates, as well as any additional information that will help young adults make an informed decision; and (c) work to increase social motivation by attempting to target not only single individuals, but communities, particularly friends' and family's attitudes regarding the importance of voting, which will increase social support for voting.

Taken together, these factors imply that young adults will vote if they perceive that they have the ability to vote, the information needed to vote, and are socially motivated to vote (i.e., if they perceive that there is social support from significant others for voting). The present results also suggest that programs whose primary goal is to register young adults to vote may turn out to be minimally effective at increasing actual voting behavior among this population. That is, although registration is a necessary precursor to 
voting, the results of the present research suggest that to increase the intention to vote and voting behavior, programs should also address other factors.

One limitation of the current research is the sample. That is, the fact that the present research used university students may limit the empirical test of the models, as well as the extent to which the present results will generalize to other samples. Specifically, the sample used in the present research is not representative of adults, as well as many young adults for many characteristics that are relevant to voting (e.g., education, level of political information, motivation). Therefore, there are limits to which the current results can be generalized. However, the use of student samples for public political behaviors (e.g., voting) is generalizable to the more general population, and only research that investigates more "private" political behaviors (e.g., decision making among leaders) should avoid student samples (Mintz, Redd, \& Vedlitz, 2006). In addition, despite greater education, recent research has suggested that most college students have comparable levels to non-college students of information and attentiveness to politics and current events (Wattenberg, 2007). Nonetheless, although the present results are supportive of the ability of the IMB constructs to predict voting behavior, additional research should test the IMB model with additional populations in additional settings.

Another limitation involves the self-report measures of voting. As past research has shown that respondents often overreport voting behavior in surveys (Silver, Anderson, \& Abramson, 1986), one should be cautious in generalizing the current results. Thus, future research should test the IMB model and validate the voting behavior of respondents (e.g., Abelson, Loftus, $\&$ Greenwald, 1992) or use another technique that reduces overreporting of behavior (e.g., face-saving response options; Belli, Traugott, Young, \& McGonagle, 1999).

Finally, although the present research found support for the predictive validity of the constructs of the IMB model, there are two notable limitations to the present test of the model. First, the present study used a very global measure of information, which included items assessing knowledge about the act of voting, the candidates, the election process, as well as the national political context. However, the IMB model posits that the information construct should measure knowledge of information directly relevant to engaging in the particular behavior (Fisher \& Fisher, 1992). Thus, future research should test the model, including more items in line with information about the act of voting. Second, as the present study did not test the full model, future research should test the utility of the full IMB model for predicting voting behavior.

Perhaps the most promising area of future research will be the opportunity to apply the highly successful IMB approach for changing behavior, 
via intervention, to non-health-related behaviors. Specifically, there is considerable empirical support for the efficacy of IMB interventions for changing HIV risk-reduction behaviors (e.g., condom use; for a review, see Fisher $\&$ Fisher, 1996). The constructs of the model are seen as highly generalizable, and the IMB approach specifies a set of procedures for designing and implementing interventions to change behavior for specific targeted populations (Fisher \& Fisher, 1993). Indeed, when conducting an intervention, it is recommended that researchers design interventions that are specific to the content deficits of the particular population. Different target populations (e.g., Blacks vs. Latinos/as) may have different deficits in information, motivation, and behavioral skills; thus, according to IMB methods, the interventions should be tailored to the particular IMB deficits of the population.

The IMB approach suggests a three-step process for implementing an intervention: (a) elicitation research with a subsample from the particular target population to identify IMB deficits; (b) design of a populationspecific intervention that is based on elicitation research; and (c) conduct a rigorous evaluation of the intervention to determine the success of the intervention at addressing the IMB deficits (Fisher \& Fisher, 2000). In sum, the findings of the present research provide initial evidence for the utility of the IMB constructs for predicting non-health behaviors and suggests that the IMB intervention approach would be successful at changing not only voting behavior of young adults, but also other non-health behaviors.

The trend of nonvoting among young adults paints a bleak picture for the future of U.S. democracy. Indeed, if young adults continue to disengage from the political system and more of these young adults reject participating in politics as they grow older, it will take less and less of a majority to determine the direction of our nation's policies. As a result, it is imperative that policymakers and scientists attempt to engage not only young adults, but all groups that have historically failed to turn out to vote on Election Day. The strength of U.S. democracy and the future political health of the U.S. may lie in our ability to engage the disengaged.

One bright spot of encouragement comes from the high rates of social volunteering among young adults (Zukin \& Jenkins, 2002). These rates indicate that young adults are exceedingly passionate, motivated, willing, and able to work to improve their communities and society as a whole. Therefore, it is evident that the key to increasing voter turnout among young adults may lie in translating this passion for positive change to voting and other forms of political participation. The present research suggests that utilizing the IMB model - as well as increasing $\mathrm{PBC}$ - is a way to translate this passion into political participation. 


\section{References}

Abelson, R. P., Loftus, E. F., \& Greenwald, A. G. (1992). Attempts to improve the accuracy of self-reports of voting. In J. M. Tanur (Ed.), Questions about questions (pp. 138-153). New York: Russell Sage Foundation.

Abramson, P. R., \& Aldrich, J. H. (1982). The decline of electoral participation in America. American Political Science Review, 76, 502-521.

Ajzen, I. (1985). From intentions to actions: A theory of planned behavior. In J. Kuhl \& J. Beckman (Eds.), Action control: From cognition to behavior (pp. 11-39). Heidelberg, Germany: Springer.

Ajzen, I., \& Fishbein, M. (1980). Understanding attitudes and predicting social behavior. Englewood Cliffs, NJ: Prentice Hall.

Ajzen, I., \& Fishbein, M. (2005). The influence of attitudes on behavior. In D. Albarracín, B. T. Johnson, \& M. P. Zanna (Eds.), The handbook of attitudes (pp. 173-221). Mahwah, NJ: Lawrence Erlbaum.

Ajzen, I., \& Madden, J. (1986). Prediction of goal-directed behavior: Attitudes, intentions, and perceived behavioral control. Journal of Experimental Social Psychology, 22, 453-474.

Ajzen, I., Timco, C., \& White, J. B. (1982). Self-monitoring and the attitudebehavior relation. Journal of Personality and Social Psychology, 41, 426435.

Albarracin, D., Johnson, B. T., Fishbein, M., \& Muellerleile, P. A. (2001). Theories of reasoned action and planned behavior as models of condom use: A meta-analysis. Psychological Bulletin, 127, 142-161.

American National Election Studies. (2005). The 1948-2004 ANES Cumulative data file: Stanford University and the University of Michigan. Retrieved February 10, 2006, from www.electionstudies.org

Armitage, C. J., \& Conner, M. (2001). Efficacy of the theory of planned behavior: A meta-analytic review. British Journal of Social Psychology, 40, 471-499.

Bassili, J. N. (1993). Response latency versus certainty as indexes of the strength of voting intentions in a CATI survey. Public Opinion Quarterly, 57, 54-61.

Belli, R. F., Traugott, M. W., Young, M., \& McGonagle, K. A. (1999). Reducing vote overreporting in surveys: Social desirability, memory failure, and source monitoring. Public Opinion Quarterly, 63, 90-108.

Blais, A. (2000). To vote or not to vote. Pittsburgh, PA: University of Pittsburgh Press.

Bowman, C. H., \& Fishbein, M. (1978). Understanding public reactions to energy proposals: An application of the Fishbein model. Journal of Applied Social Psychology, 8, 319-340. 
Botvin, G. J., Dusenbury, L., Baker, E., James-Ortiz, S., \& Kerner, J. (1989). A skills training approach to smoking prevention among Hispanic youth. Journal of Behavioral Medicine, 12, 279-296.

Carey, M. P., Maisto, S. A., Kalichman, S. C., Forsyth, A., Wright, E., \& Johnson, B. T. (1997). Enhancing motivation to reduce the risk of HIV infection for economically disadvantaged urban women. Journal of Consulting and Clinical Psychology, 65, 531-541.

Center for Information and Research on Civic Learning and Engagement. (2005). A voter turn-out time series: 1972-2004. Retrieved January 15, 2006, from www.civicyouth.org

Conner, M., \& Armitage, C. J. (1998). Extending the theory of planned behavior: A review and avenues for further research. Journal of Applied Social Psychology, 28, 1429-1464.

Craig, S. C., \& Maggiotto, M. A. (1982). Measuring political efficacy. Political Methodology, 8(3), 85-109.

Fisher, J. D., \& Fisher, W. A. (1992). Changing AIDS risk behavior. Psychological Bulletin, 111, 455-474.

Fisher, J. D., \& Fisher, W. A. (1996). The information-motivationbehavioral skills model of AIDS risk behavior change: Empirical support and applications. In S. Oskamp \& S. Thompson (Eds.), Understanding and preventing HIV risk behavior: Safer sex and drug use (pp. 100-127). Thousand Oaks, CA: Sage.

Fisher, J. D., \& Fisher, W. A. (2000). Theoretical approaches to individuallevel change in HIV-risk behavior. In J. Peterson \& R. DiClemente (Eds.), The HIV prevention handbook (pp. 3-55). New York: Plenum.

Fisher, J. D., Fisher, W. A., Misovich, S. J., Kimble, D. L., \& Malloy, T. (1996). Changing AIDS risk behavior: Effects of an intervention emphasizing AIDS risk reduction information, motivation, and behavioral skills in a college student population. Health Psychology, 15, 114 123.

Fisher, W. A., \& Fisher, J. D. (1993). A general social psychological model for changing AIDS risk behavior. In J. B. Pryor \& G. D. Reeder (Eds.), The social psychology of HIV infection (pp. 127-153). Hillsdale, NJ: Lawrence Erlbaum.

Foote, D., Martorell, R., McDivitt, J. A., Snyder, L., Spain, P. L., Stone, S., et al. (1985). Mass media and health practices evaluation in the Gambia: A report of the major findings. Menlo Park, CA: Applied Communication Technologies.

Freyman, R., \& McGoldrick, B. (2000). They pretend to talk to us, we pretend to vote: Candidates and young adults in Campaign 2000 and beyond. Third Millennium Neglection Survey. Retrieved January 15, 2006, from www. neglection2000.org/reports/dec00.html 
Green, D. P., \& Shachar, R. (2000). Habit formation and political behavior: Evidence of consuetude in voter turnout. British Journal of Political Science, 30, 561-573.

Hagger, M. S., Chatzisarantis, N. L. D., \& Biddle, S. J. H. (2002). A metaanalytic review of the theories of reasoned action and planned behavior in physical activity: Predictive validity and the contribution of additional variables. Journal of Sport and Exercise Psychology, 24, 3-32.

Hetherington, M. J. (1998). The political relevance of political trust. American Political Science Review, 92, 791-808.

Highton, B., \& Wolfinger, R. E. (2001). The first seven years of the political life cycle. American Journal of Political Science, 45, 202-209.

Jackman, R. W. (1987). Political institutions and voter turnout in the industrial democracies. American Political Science Review, 81, 405-423.

Knack, S. (1992). Civic norms, social sanctions, and voter turnout. Rationality and Society, 4, 133-156.

Lijphart, A. (1997). Unequal participation: Democracy's unresolved dilemma. American Political Science Review, 91, 1-14.

Matsusaka, J. G., \& Palda, F. (1999). Voter turnout: How much can we explain? Public Choice, 98, 431-446.

Mintz, A., Redd, S. B., \& Vedlitz, A. (2006). Can we generalize from student experiments to the real world in political science, military affairs, and international relations? Journal of Conflict Resolution, 50, 757-776.

Misovich, S. J., Martinez, T., Fisher, J. D., Bryan, A., \& Catapano, N. (2003). Predicting breast self-examination: A test of the informationmotivation-behavioral skills model. Journal of Applied Social Psychology, $33,775-790$.

Morrell, M. E. (2003). Survey and experimental evidence for a reliable and valid measure of internal political efficacy. Public Opinion Quarterly, 67, 589-602.

National Association of Secretaries of State. (1998). New Millennium Project: Why young people don't vote. Washington, DC: Author.

Netemeyer, R. G., \& Burton, S. (1990). Examining the relationships between voting behavior, intention, perceived behavioral control, and expectation. Journal of Applied Social Psychology, 20, 661-680.

Niemi, R. G., \& Hanmer, M. J. (2006, January). Voter registration and turnout among college students. Paper presented at the annual meeting of the American Political Science Association, Philadelphia, PA.

Plutzer, E. (2002). Becoming a habitual voter: Inertia, resources, and growth in young adulthood. American Political Science Review, 96, 4156.

Rosenstone, S. J., \& Hansen, J. M. (1993). Mobilization, participation, and democracy in America. New York: Macmillan. 
Schlozman, K. L. (2002). Citizen participation in America: What do we know? Why do we care? In I. Katznelson \& H. V. Miller (Eds.), Political science: The state of the discipline (pp. 433-461). New York: W. W. Norton.

Sheeran, P., \& Taylor, S. (1999). Predicting intentions to use condoms: A meta-analysis and comparison of the theories of reasoned action and planned behavior. Journal of Applied Social Psychology, 29, 1624-1675.

Sheppard, B. H., Hartwick, J., \& Warshaw, P. R. (1988). The theory of reasoned action: A meta-analysis of past research with recommendations for modifications and future research. Journal of Consumer Research, 15, $325-342$.

Silver, B. D., Anderson, B. A., \& Abramson, P. R. (1986). Who over-reports voting? American Political Science Review, 80, 613-624.

Singh, K., Leong, S. M., Tan, C. T., \& Wong, K. C. (1995). A theory of reasoned action perspective of voting behavior: Model and empirical test. Psychology and Marketing, 12, 37-51.

Strate, J. M., Parrish, C. D., Elder, C. D., \& Ford, C. (1989). Life span civic development and voting participation. American Political Science Review, $83,443-464$.

Teixeira, R. A. (1992). The disappearing American voter. Washington, DC: The Brookings Institution.

U.S. Census Bureau. (2004). Voting and registration in the election of November 2004 (Current Population Survey). Retrieved March 10, 2007, from www.census.gov/prod/2006pubs/p20-556.pdf

Verba, S., Schlozman, K. L., \& Brady, H. E. (1995). Voice and equality: Civil voluntarism in American politics. Cambridge, MA: Harvard University Press.

Wattenberg, M. P. (2005, March). Elections: Turnout in the 2004 Presidential election. Presidential Studies Quarterly, 35, 138-146.

Wattenberg, M. P. (2007). Is voting for young people? New York: Pearson Longman.

Wolfinger, R. E., Glass, D. T., \& Squire, P. (1990). Predictors of electoral turnout: An international comparison. Policy Studies Review, 9, 551-574.

Wolfinger, R. E., \& Rosenstone, S. J. (1980). Who votes? New Haven, CT: Yale University Press.

Zukin, K., \& Jenkins, A. (2002). The civic and political health of the nation: A generational portrait. Center for Information and Research on Civic Learning and Engagement. Retrieved January 15, 2006, from www. circle.org 